\title{
Transição da docência para o empreendedorismo: motivos e dinâmicas de inserção.
}

\section{Resumo}

Este estudo investigou fatores influenciadores da transição da docência para o empreendedorismo, assim como seus principais motivos. Entrevistaram-se vinte e cinco docentes, de universidades públicas e privadas, que se direcionaram para a carreira empreendedora. Os dados foram analisados com ajuda do Software QDA Miner. Contatos com docentes empreendedores estrangeiros adquiriram importância para a transição, motivada mais pelos seus desafios do que por insatisfação. Os discursos dos docentes empreendedores, acordes com o discurso empresarial contemporâneo, enfatizaram competitividade, desempenho e inovação, opondo-se ao discurso da universidade, considerado ainda bastante reticente quanto à associação entre geração/disseminação de conhecimento e obtenção de ganhos financeiros.

Palavras-chave: Transição de Carreira. Empreendedorismo. Motivos e dinâmicas de Inserção

\section{Transition from teaching to entrepreneurship: statement and dynamics of incorporation.}

\begin{abstract}
This study investigated the factors which influence the transition from teaching to entrepreneurship, as well as its main reasons. Twenty-five teachers were interviewed from public and private universities who started a career in entrepreneurship. The data were analyzed using the QDA Miner Software. Contacts with foreing entrepreneurial teachers became important for the transition motivated more by the challenges than by dissatisfaction. The entreprenurial teachers' speeches, in line with the contemporary entreprenurial speech, enphasize competitivity, performance and innovation in opposition to the university speech, which is still considered hesitant to the association between generation/dissemination of knowledge and making a finantial profit.
\end{abstract}

Keywords: Career Transition. Entrepreneurship. Reasons and. insertion dynamics.

(1) Professora do Programa de Doutorado e Mestrado em Administração da Fundação Mineira de Educação e Cultura, Faculdade de Ciências Econômicas, Administrativas e Contábeis, FUMEC. (zeliamk@gmail.com)

(2) Professor do Programa de Doutorado e Mestrado em Administração da Fundação Mineira de Educação e Cultura, Faculdade de Ciências Econômicas, Administrativas e Contábeis, FUMEC. (violi@superig.com.br)

(3) Professor do curso de Administração e Coordenador do Núcleo de Pesquisa e Pós-Graduação da Faculdade Promove Minas Gerais. (silvinosantos.acad@gmail.com) 


\section{Introdução}

O contexto atual tem-se caracterizado por mudanças rápidas e constantes, dentre as quais se destacam: a globalização, a desregulamentação econômica, as inovações tecnológicas, a ênfase da indústria para os setores de manufaturados e baseados no conhecimento, a reestruturação organizacional, a intensificação dos processos de terceirização, assim como o aumento do contingente da força de trabalho.

Esse contexto, marcado por grandes desafios e por quebras de paradigmas, tem incentivado docentes pesquisadores a adotar comportamentos mais ousados, rompendo os limites da academia para adentrar no empreendedorismo, por vezes, via incubadoras de empresas existentes dentro das universidades atentas às mudanças, como Universidades Empreendedoras ou como universidades que se colocam na relação universidade - governo - empresa e inovação (IPIRANGA; FREITAS; PAIVA, 2010; NASSIF et al., 2011; GUERRA; GOMES; CHENG, 2011; SOUZA; TAKAHASHI, 2014).

O processo empreendedor pode ser visto como a identificação de oportunidades inovadoras, as quais podem ou não ser exploradas através da criação de novas organizações (SHANE; VENKATARAMAN, 2000). Para Peters, Hisrich e Sheperd (2009), empreendedorismo é o processo de criar algo diferente e com valor, dedicando tempo e o esforço necessários, assumindo os riscos financeiros, psicológicos e sociais correspondentes e recebendo as consequentes recompensas da satisfação econômica e pessoal. Segundo Silva, Reis e Sturion (2012), é preciso que os empreendedores captem oportunidades, assumam riscos calculados, se antecipem aos fatos e percebam como será a organização no futuro. Assim, a exploração de uma nova oportunidade pode ocorrer de outros modos: por meio do desenvolvimento de novos produtos ou processos, ou por meio de incubadoras de empresas.

Nicolau e Birley (2003), citados por Duberley, Cohen e Leeson (2007), consideram que as incubadoras de empresas envolvem essencialmente a transferência da tecnologia de base, de uma instituição acadêmica, para uma nova empresa. A nova empresa pode contratar o inventor acadêmico na função de diretor da empresa, e esse ainda pode permanecer filiado à instituição acadêmica.

Incubadoras de empresas são organizações que abrigam empreendimentos nascentes, geralmente oriundos de pesquisa científica, cujo projeto implica inovações. Essas organizações oferecem espaços e serviços subsidiados que favorecem o empreendedorismo e o desenvolvimento de serviços, produtos e/ou processos (BAETA; SANTARITA, 2008). As primeiras incubadoras de empresas surgiram no Brasil na década de oitenta e, desde então, o número de incubadoras vem crescendo sensivelmente.

No exame da literatura produzida sob o campo semântico do empreendedorismo, percebese um conjunto de temas afins e complementares, como: a transferência de tecnologia da universidade para a empresa (SANTANA; PORTO, 2009; MUSCIO, 2010; PÓVOA; RAPINI, 2010; CLOSS et al., 2012); a associação, nas universidades, do empreendedorismo e da inovação ao mercado (DOMINGUES, 2012); o processo de produção e disseminação de informação tecnológica que leva a inovação para o setor produtivo pela transformação do conhecimento científico e tecnológico em resultado econômico (CASTRO; JANNUZZI; MATTOS, 2007); a relação entre empreendedorismo, inovação e universidade (GUERRA; TEODORO; CHENG, 2011); empreendedorismo, tecnologia e educação (SILVA, REIS, STURION, 2012); o papel da universidade empreendedora num contexto de mudanças, que requer autonomia para elas, mas que implica outros problemas, como a internacionalização da educação e o conceito de sustentabilidade (AUDI; MOROSINI, 2006); cooperação, quanto ao empreendedorismo, entre universidade, empresas e governo (IPIRANGA; FREITAS; PAIVA, 2010); características do comportamento empreendedor (SOUZA et al., 2013); a carreira do empreendedor (este em sentido amplo) e o conceito de carreiras sem fronteiras (GUEDES, 2009); as carreiras sem fronteiras, com foco no afrouxamento dos vínculos entre indivíduos 
e organizações, provocado pelo crescimento da importância do mercado (BENDASSOLI; WOOD JR., 2010); a relação entre profissionais técnicos, portadores de diplomas de curso superior, o empreendedor, o empreendedorismo e a transição de carreira (PINOTTI, 2009); profissão, âncoras (sendo o empreendedorismo uma delas), transição e metáforas de carreira (KILIMNIK; CASTILHO; SANT'ANNA, 2004; MACHADO, 2009; SANT'ANNA, 2008; SANTOS; ABRAHIM, 2008); empreendedorismo, carreira, emancipação e mudança (BARLACH; MALVEZZI, 2012); âncoras e metáforas de carreira entre universitários, dentre as quais se inclui o empreendedorismo, a ideia de escalada e de desafio puro (GOMES et al., 2012).

Esses temas, sinteticamente, abordam a relação entre empreendedorismo e universidade; empreendedorismo, universidade e mercado; empreendedorismo, carreira e mudança; carreira, âncoras e metáforas de carreira, esboçando uma abordagem bastante ampla, em termos temporais, de 2006 a 2013, e em termos de conteúdo. Entretanto, não refletem, especificamente, sobre a transição da docência para o empreendedorismo, objeto deste texto. Ao tratarem de assuntos pertinentes à transição, à carreira e ao empreendedorismo, como competitividade, lucro, mercado e universidade empreendedora, enfatizam a necessidade e a importância de se analisar os fatores que influenciam determinados professores a saírem de suas zonas de conforto e a se direcionem para o empreendedorismo.

Surge daí a proposta desta pesquisa: investigar se e como as mudanças contextuais afetama carreira dos profissionais do ambiente acadêmico, especialmente no processo de transição para uma carreira empreendedora por meio de incubadoras de empresas. E, também, compreender como a transição de carreira é percebida e vivenciada por esses profissionais docentes. A transição de carreira pode ser definida como o período No qual um indivíduo está trocando de papel ou, em outras palavras, buscando um papel cujo objetivo seja diferente. De modo alternativo, também pode ser usada para descrever uma mudança na orientação do indivíduo para uma função que já detém, ou seja, uma transição em seu estado subjetivo (LOUIS, 1980).

Duberley, Cohen e Leeson (2007), sintetizando ideias de diversos autores, apontam que há muitos níveis de transição em toda a carreira de um indivíduo, iniciando com a transição da escola para o trabalho e terminando com a transição para a aposentadoria plena. Sustentam que esses momentos formam a base sobre a qual as pessoas dão sentido tanto a suas carreiras quanto a vidas. O que representa um ponto de ruptura em relação ao status quo, tal como ocorre com a transição de uma carreira científica tradicional e com base universitária para uma forma emergente de carreira: a de empreendedor.

A presente pesquisa se inspirou em estudo realizado por Duberley, Cohen e Leeson (2007) com docentes pesquisadores que transitaram para o empreendedorismo por meio de incubadoras de empresas, no Reino Unido.

\section{Fundamentação teórica}

\section{Transições de carreira}

Riverin-Smard (1993) desenvolve a ideia de que a transição de carreira consiste em um fenômeno que afeta atualmente a maioria dos adultos e se configura como um processo dinâmico, com repercussões em outras esferas além da profissional. Esta autora define, assim, a transição de carreira como uma diferente etapa do desenvolvimento profissional, geralmente suscitada pela perda do emprego, que se revela ser igualmente uma transição socioprofissional.

Algumas transições são involuntárias, isto é, provocadas pelos eventos da vida, por um divórcio ou uma perda de emprego; outras mudanças são voluntárias, pois a própria pessoa pode se colocar em uma posição de transição, por exemplo, ao decidir retornar aos estudos no decorrer da vida adulta (RIVERIN-SIMARD, 1993). 
Para Louis (1980), a transição de carreira seria definida como o período em que um indivíduo está trocando de papéis, ou em busca de um papel cujo objetivo seja diferente; pode ser descrita como uma mudança na orientação do indivíduo para uma função que já detém, ou seja, uma transição em seu estado subjetivo.

As transições de carreira, no contexto das grandes transformações da sociedade, configuram-se como um dos subtemas mais relevantes, justamente por constituírem consequência natural do declínio da carreira tradicional, intimamente associada à determinada profissão e/ou organização e à emergência da carreira proteana, que implica constantes mudanças (BARUCH, 2011; TIEPPO et al., 2011).

De acordo com Veloso (2012), as transformações sociais que proporcionam a emergência de carreiras sem fronteiras, no que se refere a organizações, funções e profissões (fronteiras objetivas), e também a crenças, padrões e atitudes pessoais (fronteiras subjetivas), tornam mais frequentes as transições de carreira. E essas podem ser motivadas por situações que impõem a adaptação a uma nova realidade: a perda de um emprego, uma proposta de mudança de trabalho, ou uma decisão ou redirecionamento do profissional em busca de novos desafios.

Essa última modalidade é objeto do presente estudo, com a abordagem de transições voluntárias de docentes e pesquisadores para o empreendedorismo, que podem ser denominadas de transições interprofissão, segundo Louis (1980), referindo-se a um dentista que se torna advogado, um empregado que se torna empregador, ou um empresário que se torna acadêmico e vice-versa.

Para Duberley, Cohen e Leeson (2007), um acentuado número de estudos anteriores, que exploraram as transições de carreira, tem suas origens na psicologia do desenvolvimento e aconselhamento de carreira. A ênfase desses estudos se pauta no indivíduo e nas análises decorrentes dessas tradições, cujo foco reside na forma como as características de personalidade ou outros atributos influenciam o curso de uma carreira e os processos iniciais de escolha profissional (NICHOLSON; WEST, 1988).

Duberley, Cohen e Leeson (2007) afirmam que, por décadas, mesmo havendo demandas por uma teoria sobre transição ocupacional, que considerasse as causalidades contextuais e individuais, essas raramente foram ensejadas. As autoras apontam a necessidade de pesquisas que possam analisar as transições dos indivíduos nos diferentes grupos profissionais, vivenciando mudanças institucionais de grande escala. Argumentam que esquemas para compreensão das transições de carreira devem transcender uma análise simplista e dualista, avaliando as relações recursivas entre mudanças institucionais e mudanças individuais de carreira.

Identificando algumas características já apresentadas na literatura no que se refere à carreira científica, Duberley, Cohen e Mallon (2006) constatam que, entre elas, as carreira são influenciadas: pela tensão entre o contexto organizacional e o profissional, pela tensão entre as dimensões acadêmicas e corporativas das universidades, e pelo contexto pessoal e familiar.

Duberley, Cohen e Leeson (2007) realizaram um estudo com 23 cientistas acadêmicos que fundaram incubadoras de empresas, privilegiando a análise da interação entre as mudanças institucionais e a transição de carreira. Ao examinar a forma como os cientistas têm realizado mudanças em sua carreira, inseridos em um contexto global de mudanças institucionais, foi possível destacar as complexas e dinâmicas inter-relações no trabalho. No grupo estudado, mais da metade da amostra optou por permanecer na academia britânica, porém mantendo envolvimento com incubadoras de empresas. Os respondentes, entre outros resultados, manifestaram a frustração de que, apesar de realizada a transição para o empreendedorismo, suas organizações empregadoras se mantiveram atrasadas e continuaram a julgá-los com base em medidas tradicionais de desempenho acadêmico, ou seja, produção de artigos acadêmicos. 


\section{Empreendedorismo}

A palavra empreendedor tem sua origem no latim imprendere, significando decidir, executar tarefa difícil e laboriosa. Posteriormente, a palavra evolui no francês para entrepreneur, significando "aquele que assume risco e começa algo novo" (DORNELAS, 2005, p. 9).

Segundo Drucker (1986), o empreendedorismo está associado ao comportamento, tendo como base conceito e teoria. Assim, o empreendedor codifica a mudança como uma oportunidade e não como um obstáculo, e consegue explorá-la: concebe uma nova forma de agir e implanta novas ideias. Torna-se um agente de mudanças e potencializa sua competência para a gestão.

O empreendedorismo é um fenômeno de abrangência internacional, que tem sido muito discutido nos meios acadêmicos. A literatura, ao retomar o tema, relaciona-o a fatores como desenvolvimento econômico, geração de empregos e riqueza. Trata-se de uma atividade exercida pela humanidade há muito tempo. Atrelados a isso, o progresso e a evolução das sociedades vêm ocorrendo continuamente, porque as pessoas identificam oportunidades de melhoria e crescimento sob aspectos diversos, permitindo, assim, um crescimento sustentável do desenvolvimento humano através dos séculos (RIMOLI et al., 2004).

Schumpeter (1997) já descrevia os empreendedores como indivíduos inovadores que conduziam o processo "criativo/destrutivo" do capitalismo. O empreendedorismo, que se difunde desde Schumpeter (1997), destaca a importância do empreendedor no desenvolvimento econômico e na sobrevivência do capitalismo. Para esse autor, o empreendedor tem uma função social, por provocar inovação e crescimento econômico. Assim, o conceito de inovação e novidade torna-se parte integrante do de empreendedorismo e a figura do empreendedor passa a ser estudada em muitas áreas de conhecimento.

O Global Entrepreneurship Monitor - GEM (RELATÓRIO, 2007), um grupo de pesquisa formado pelo Babson College e pela London Business School, vem acompanhando sistematicamente as estatísticas de empreendedorismo em mais de 40 países de todos os continentes, marcando presença, também, no Brasil. Em seus estudos, o GEM (RELATÓRIO, 2007) caracteriza os empreendedores iniciais como aqueles cujos empreendimentos têm até 42 meses de vida e os empreendedores estabelecidos como aqueles à frente de empreendimentos com tempo superior a este período. No momento atual, o empreendedorismo é um fenômeno global que está despertando o interesse de grupos investidores, de governantes, de universidades e instituições públicas e privadas que almejam constituir novas atividades geradoras de riquezas e o percebem como um instrumento de desenvolvimento econômico e social (FILION; DOLABELA, 2000; TAVARES; MOURA; ALVES, 2013).

Embora as pesquisas sobre as características do empreendedor tenham dominado a cena acadêmica por um longo tempo, tanto na visão schumpeteriana como na de comportamento, desenvolvida por McClelland, não há necessidade de manter esforços para compreender as diferenças entre quem é um empreendedor e quem não é, bem como conhecer sobre as suas características (SARASVATHY, 2004). Dentro dessa linha de pensamento, considera-se mais relevante analisar condicionantes intrínsecos e extrínsecos do empreendedorismo. No caso do presente estudo, o foco consiste em identificar os principais fatores contextuais que influenciam a transição do docente que deseja se tornar um empreendedor.

\section{Metodologia}

\section{Tipo de abordagem e de pesquisa}

Trata-se de uma pesquisa com abordagem qualitativa, que, de acordo com Vieira (2004) atribui importância fundamental à descrição detalhada dos fenômenos e dos elementos que o envolvem, aos depoimentos dos atores sociais envolvidos, aos discursos, aos significados e aos contextos. Conforme esse autor (2004), a pesquisa qualitativa normalmente permite descrever de forma rica e fundamentada o objeto de estudo, possibilita explicar processos localizados em contextos identificáveis. Além do mais, ela auxilia o pesquisador a se adiantar às concepções inicialmente concebidas ou mesmo fazer uma revisão de sua estrutura teórica. 
Segundo Alves-Mazzotti e Gewandsznajder (1999), na pesquisa qualitativa há a necessidade de contato direto e prolongado com o campo, para captar os significados dos comportamentos observados. Ainda de acordo com eles, a pesquisa qualitativa é a escolha mais adequada quanto se objetiva:

Descrever a complexidade de determinado problema;

Analisar a interação de certas variáveis;

Compreender e classificar processos dinâmicos vividos por grupos sociais;

Contribuir para o processo de mudança de determinado grupo;

Possibilitar o entendimento em profundidade das particularidades do comportamento dos indivíduos.

A presente pesquisa abrangeu todos os objetivos acima citados, justamente pelo fato de seu objeto de pesquisa - o docente pesquisador em transição para o empreendedorismo estar inserido em um contexto mutante e de elevada complexidade, passando ele próprio por grandes mudanças no que se refere a atitudes, conhecimentos, habilidades e comportamentos.

Submeteu-se o projeto ao conselho de ética da instituição a que os pesquisadores se vinculam e obteve-se a anuência do pesquisado, por meio de um termo de consentimento livre e esclarecido; especificando-se que qualquer publicação deste material excluiria toda possibilidade de sua identificação por parte de terceiros e de que ele estaria autorizado a encerrar sua participação no trabalho a qualquer momento que julgasse necessário.

\section{Método de pesquisa e seleção dos entrevistados}

Foi utilizado o método de Estudo de Campo, tendo em vista que foram pesquisados diversos docentes em transição de carreira para o empreendedorismo. De acordo com Vergara (2004, p. 47), uma "pesquisa de campo é investigação empírica realizada no local onde ocorre ou ocorreu um fenômeno ou que dispõe de elementos para explicá-lo. [...]".

As entrevistas foram realizadas com docentes pesquisadores que se direcionaram para o empreendedorismo, alguns deles por meio de incubadoras de empresas.

Os entrevistados foram selecionados de acordo com critérios pré-estabelecidos: 1) ter realizado, de modo parcial ou total, a transição do ambiente acadêmico para o empreendedorismo; 2) tê-la feito preferencialmente, mas não necessariamente, por meio de incubadoras de empresas; 3 ) tê-la executado há mais de um ano e há menos de cinco anos. Foi utilizada a estratégia de escolha intencional e por acessibilidade, conjugada com a técnica "bola de neve" (ARBER, 2001), com o objetivo de obter um conjunto diversificado de docentes pesquisadores, capaz de fornecer ricas e diversas informações sobre o tema em estudo.

Devido ao fato de as incubadoras de empresas estarem situadas predominantemente em universidades públicas, esperava-se que o profissional a ser entrevistado atuasse, ou tivesse atuado, em instituições dessa natureza. Isso se confirmou no decorrer do estudo. Apesar de não ter havido restrições quanto à participação de docentes de universidades particulares e nem exigência de que o direcionamento para o empreendedorismo tivesse ocorrido necessariamente por meio de incubadoras.

\section{Instrumentos e procedimentos de coleta de dados}

Foram realizadas 25 entrevistas semiestruturadas, nas cidades de Belo Horizonte e Curitiba, cidades essas escolhidas pelo critério de maior acessibilidade e conveniência para os pesquisadores. As entrevistas foram abertas e em profundidade, possibilitando aos participantes a oportunidade de se manifestar de acordo com seu próprio modo de falar, 
introduzindo questões que foram entendidas como relevantes e refletindo sobre elas. A duração média da entrevista foi de uma hora.

Os depoimentos em entrevistas foram gravados e transcritos na íntegra, para análise. Conforme dito anteriormente, os entrevistados assinaram um termo de consentimento declarado. Os pesquisadores foram orientados a exercer um mínimo de interferência, para as respostas e proposições serem analisadas da maneira mais imparcial possível e para garantir ao trabalho um caráter rigoroso, como se espera em uma investigação científica.

\section{Tratamento e análise dos dados}

O conteúdo das entrevistas foi transcrito, organizado e analisado à luz dos conceitos da análise de conteúdo, conforme proposto por Bardin (2006).

Segundo Bardin (2006), pode-se entender por análise de conteúdo um conjunto de técnicas de análise de comunicações que contêm informação sobre o comportamento humano, atestado por uma fonte documental. Na análise de conteúdo, são utilizados procedimentos sistemáticos e objetivos para descrever o conteúdo das mensagens, os indicadores quantitativos ou não quantitativos, que possibilitem inferir os conhecimentos relativos às condições de produção e/ ou recepção das variáveis inferidas dessas mensagens (BARDIN, 2006).

Como ferramenta auxiliar para a análise de conteúdo, foi utilizado o QDA Miner, software aplicado à análise qualitativa, que permite a quantificação de dados textuais codificados. De acordo com Moro e Sanchez-Criado (2005), esse software permite a realização de análises estatísticas, sem perder de vista as unidades de sentido de um texto.

Com a utilização do QDA Miner para análise das entrevistas, algumas das dimensões de análise previamente estabelecidas foram alteradas e todas se desdobraram em subcategorias, denotando o maior detalhamento que esse software proporciona à análise dos dados da pesquisa. As análises foram realizadas por dois assistentes de pesquisa, mediante a supervisão do coordenador da pesquisa. Coube a ele agrupar determinadas subdimensões e suprimir outras, com objetivo de obter dimensões válidas, pertinentes e, ou, adequadas (MORAES, 1999).

\section{Resultados da pesquisa \\ Caracterização dos entrevistados}

De acordo com o Quadro 1, foram entrevistados 25 pesquisadores e docentes de áreas diversas, em transição de carreira para o empreendedorismo, de universidades públicas e privadas, com idades entre 33 a 66 anos. Quanto ao sexo, 23 são do sexo masculino. No que se refere à qualificação, 19 são doutores (dentre eles, 12 pós-doutores), quatro são mestres, um é especialista e outro é somente graduado. Treze docentes atuam em uma universidade pública federal do Estado de Minas Gerais e onze em universidades privadas, sendo seis pertencentes a uma universidade particular, situada no Estado do Paraná. Somente um atua em um centro tecnológico federal de Minas Gerais, totalizando 25 pesquisados.

Sobre as empresas criadas por esses professores, a maior parte atua na área de Biologia e Tecnologia de Informação, fazendo parte da pesquisa, também, uma produtora musical e duas produtoras de bebidas, além de duas da área de Química, tendo uma parte considerável dessas empresas (onze) passado por processos de incubação. 
Quadro 1 - Caracterização dos entrevistados

\begin{tabular}{|c|c|c|c|c|c|c|}
\hline $\mathbf{N}^{\circ}$ & Idade & $\begin{array}{l}\text { Grau de } \\
\text { Instrução }\end{array}$ & $\begin{array}{l}\text { Área de } \\
\text { Formação }\end{array}$ & $\begin{array}{l}\text { Área de } \\
\text { Atuação }\end{array}$ & $\begin{array}{l}\text { Natureza da } \\
\text { Instituição }\end{array}$ & $\begin{array}{l}\text { Área de Atuação do } \\
\text { Empreendimento }\end{array}$ \\
\hline 1 & 60 & Pós-Doutor & $\begin{array}{l}\text { Engenharia } \\
\text { Elétrica }\end{array}$ & $\begin{array}{l}\text { Ciências da } \\
\text { Comput. }\end{array}$ & Univ. pública/MG & $\begin{array}{l}\text { TI - Tecnologia da } \\
\text { Informação }\end{array}$ \\
\hline 2 & 51 & Pós-Doutor & $\begin{array}{l}\text { Ciências } \\
\text { Biológicas }\end{array}$ & $\begin{array}{l}\text { Ciências } \\
\text { Biológicas }\end{array}$ & Univ. pública/MG & Biotecnologia \\
\hline 3 & 63 & Pós-Doutor & Química & Química & Univ. pública/MG & Bioquímica \\
\hline 4 & 55 & Graduado & $\begin{array}{l}\text { Tecnologia da } \\
\text { Qualidade e } \\
\text { Normalização }\end{array}$ & $\begin{array}{l}\text { Engenharia } \\
\text { Elétrica }\end{array}$ & $\begin{array}{l}\text { Centro Tec. } \\
\text { Federal/MG }\end{array}$ & $\begin{array}{l}\text { Eletrônica/Tecnologia da } \\
\text { Informação }\end{array}$ \\
\hline 5 & 36 & Pós-Doutor & \begin{tabular}{|l|} 
Ciências \\
Biológicas
\end{tabular} & Bioquímica & Univ. privada/MG & Biotecnologia (Incubada) \\
\hline 6 & 47 & Pós-Doutor & $\begin{array}{l}\text { Engenharia } \\
\text { Mecânica }\end{array}$ & $\begin{array}{l}\text { Engenharia } \\
\text { Mecânica }\end{array}$ & Univ. pública/MG & Biotecnologia/Saúde \\
\hline 7 & 56 & Pós-Doutora & Física & Química & Univ. pública/MG & Nanotecnologia \\
\hline 8 & 65 & Pós-Doutor & $\begin{array}{l}\text { Engenharia } \\
\text { Mecânica }\end{array}$ & $\begin{array}{l}\text { Ciências da } \\
\text { Computação }\end{array}$ & $\begin{array}{l}\text { Universidade } \\
\text { pública/MG }\end{array}$ & $\begin{array}{l}\text { TI - Tecnologia da } \\
\text { Informação }\end{array}$ \\
\hline 9 & 40 & Pós-Doutor & Química & Química & Univ. pública/MG & $\begin{array}{l}\text { Química/Sustentabilidade } \\
\text { (Incubada) }\end{array}$ \\
\hline 10 & 53 & Pós-Doutora & Química & Química & Univ. pública/MG & Bioeletrônica \\
\hline 11 & 51 & Pós-Doutor & $\begin{array}{l}\text { Medicina } \\
\text { Veterinária }\end{array}$ & $\begin{array}{l}\text { Biologia } \\
\text { Molecular }\end{array}$ & Univ. pública/MG & Biotecnologia \\
\hline 12 & 52 & Doutor & Física & $\begin{array}{l}\text { Engenharia } \\
\text { Metalúrgica }\end{array}$ & Univ. pública/MG & Consultoria \\
\hline 13 & 42 & Doutor & $\begin{array}{l}\text { Medicina } \\
\text { Veterinária }\end{array}$ & $\begin{array}{l}\text { Administração/ } \\
\text { Marketing }\end{array}$ & Univ. privada/MG & $\begin{array}{l}\text { Marketing/Pesquisas } \\
\text { mercadológicas }\end{array}$ \\
\hline 14 & 56 & Pós-Doutor & Física & Física & Univ. pública/MG & $\begin{array}{l}\text { Física } \\
\text { (Incubada) }\end{array}$ \\
\hline 15 & 37 & Especialista & Administração & Administração & Univ. Privada/PR & Produtora de bebidas \\
\hline 16 & 33 & Pós-Doutor & Administração & Administração & Univ. Privada/PR & $\begin{array}{l}\text { Produtos tecnológicos } \\
\text { para ciência, assessoria e } \\
\text { consultoria empresarial e } \\
\text { educacional }\end{array}$ \\
\hline 17 & 60 & Doutor & Música & Música & Univ. pública/MG & Produtor Musical \\
\hline 18 & 40 & Doutor & $\begin{array}{l}\text { Biologia/ } \\
\text { Química }\end{array}$ & $\begin{array}{l}\text { Biologia/ } \\
\text { Química }\end{array}$ & Univ. Privada/MG & Biologia/ Química/Incubada \\
\hline 19 & 35 & Doutor & $\begin{array}{l}\text { Engenharia } \\
\text { Elétrica }\end{array}$ & $\begin{array}{l}\text { Engenharia } \\
\text { Elétrica }\end{array}$ & Univ. Privada/MG & Eletrônica/Incubada \\
\hline 20 & 38 & Mestre & $\begin{array}{l}\text { Engenharia } \\
\text { Elétrica }\end{array}$ & $\begin{array}{l}\text { Ciências da } \\
\text { Comp. }\end{array}$ & Univ. Privada/MG & $\begin{array}{l}\text { TI - Tecnologia da } \\
\text { Informação (incubada) }\end{array}$ \\
\hline 21 & 35 & Mestre & Odontologia & $\begin{array}{l}\text { Mestrado em } \\
\text { Microbiologia }\end{array}$ & Univ. Privada/PR & $\begin{array}{l}\text { Empreendedor de internet } \\
\text { - Treino de corrida em MP3/ } \\
\text { incubada }\end{array}$ \\
\hline 22 & 43 & Mestre & $\begin{array}{l}\text { Engenharia } \\
\text { Elétrica }\end{array}$ & $\begin{array}{l}\text { Engenharia } \\
\text { Elétrica }\end{array}$ & Univ. Privada/PR & $\begin{array}{l}\text { Dispositivos para instalações } \\
\text { elétricas/incubada }\end{array}$ \\
\hline 23 & 32 & Mestre & $\begin{array}{l}\text { Engenharia de } \\
\text { Bioprocessos e } \\
\text { Biotecnologia }\end{array}$ & Biotecnologia & Univ. Privada/PR & $\begin{array}{l}\text { Leveduras, P\&D e Projetos } \\
\text { de processos fermentativos } \\
\text { (incubada) }\end{array}$ \\
\hline 24 & 43 & Doutor & Química & $\begin{array}{l}\text { Química/gestão } \\
\text { ambiental/ } \\
\text { Biotecnologia }\end{array}$ & Univ. Privada/PR & $\begin{array}{l}\text { Produtora de bebidas } \\
\text { (incubada) }\end{array}$ \\
\hline 25 & 57 & Doutor & $\begin{array}{l}\text { Engenharia/ } \\
\text { Administração }\end{array}$ & Administração & Univ. pública/MG & $\begin{array}{l}\text { Biotecnologia (investidor de } \\
\text { empresa incubada) }\end{array}$ \\
\hline
\end{tabular}




\section{Resultados propriamente ditos}

Conforme dito no tópico de metodologia, a partir das análises das entrevistas identificaramse nove dimensões, as quais reúnem códigos ou subdimensões que detalham os aspectos representados em cada uma delas. Tendo em vista o objetivo geral da pesquisa - caracterizar e avaliar os fatores contextuais que influenciam a carreira acadêmica e o processo de transição de carreira para o empreendedorismo, assim como analisar como a transição é percebida pelos docentes empreendedores - tais dimensões foram organizadas respeitando uma sequência lógica, de modo a possibilitar ao leitor uma compreensão mais clara possível do que cada uma representa. No presente estudo serão abordados os resultados referentes às dimensões consideradas mais centrais em relação ao referido objetivo geral. Os aspectos levantados, contudo, possuem interfaces, pois se referem a realidades sociais complexas. Dessa forma, as subdivisões dentro de cada categoria ou dimensão não são excludentes entre si, de maneira que os percentuais das tabelas podem vir a exceder o total de $100 \%$.

\section{Fatores influenciadores e motivos da transição}

Nessa pesquisa, os fatores influenciadores da decisão de transitar para oempreendedorismo se desdobraram em: 1) Trajetória familiar e profissional; e 2) Motivos para a transição (FIGURA 1). Nessa figura, são destacadas as experiências na trajetória dos entrevistados, nos âmbitos acadêmico, profissional e pessoal, bem como fatores (positivos e negativos) que os levaram a desenvolver um empreendimento.

Figura 1 - Aspectos influenciadores na transição para o empreendedorismo

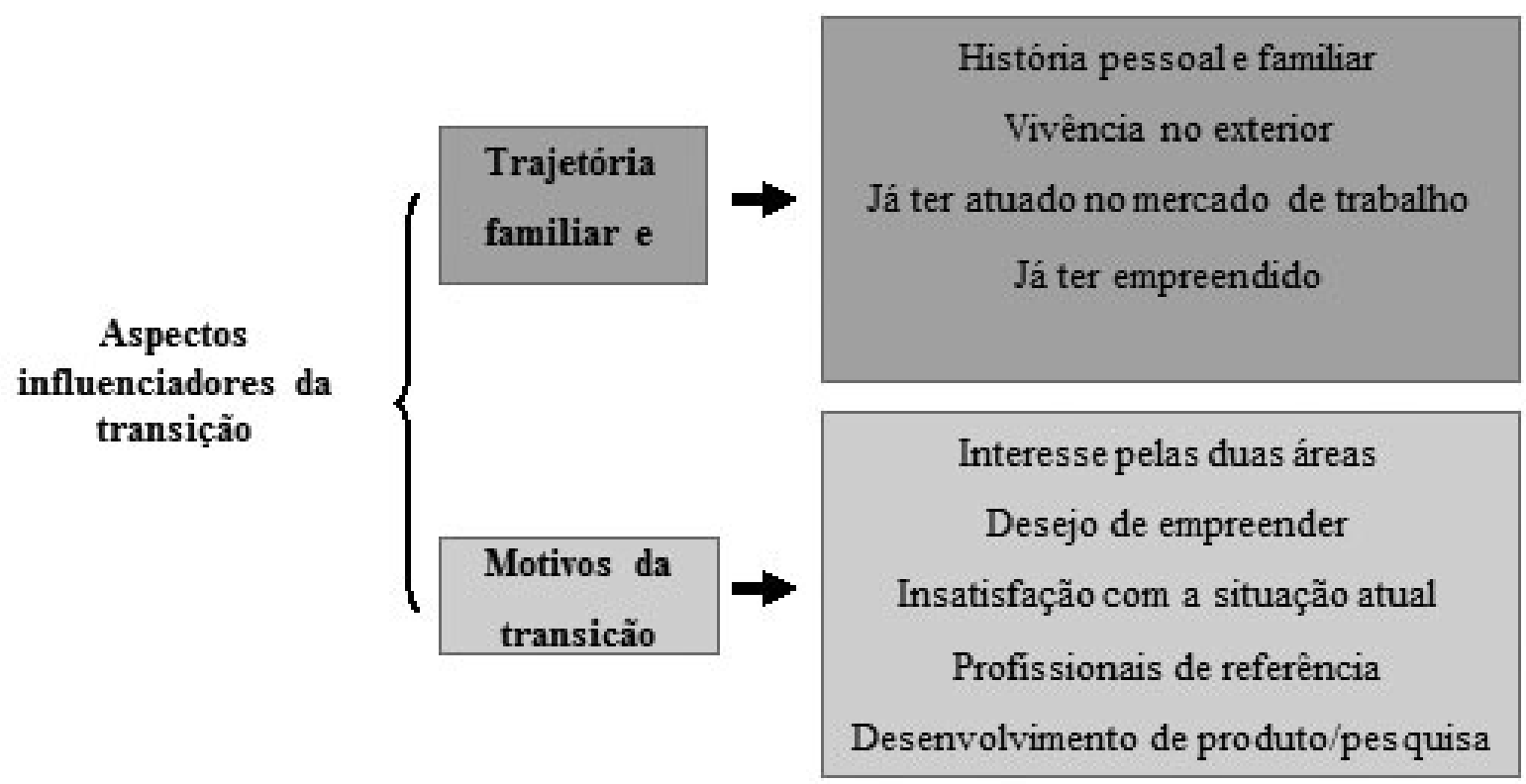

Fonte: os autores

\section{Fatores influenciadores da transição}

Acerca da trajetória profissional e familiar (TABELA 1), foram identificados: a vivência de um determinado período no exterior (30 citações em $54,2 \%$ das entrevistas); história pessoal e influência do contexto familiar (20 citações, em 50,0\%); ter experiência de mercado (19 citações, em 25\%). Alguma experiência com empreendimentos, antes de se tornar professor, foi citada por apenas um entrevistado. Vale observar que um mesmo entrevistado podia citar mais de um tipo de experiência como facilitador da transição para o empreendedorismo, o mesmo ocorrendo com outras dimensões investigadas. 
Tabela 1 - Trajetória profissional e familiar

\begin{tabular}{|c|c|c|c|}
\hline \multicolumn{4}{|c|}{ Trajetória profissional e familiar } \\
\hline Código & Descrição & Citações & $\begin{array}{l}\text { Entrevistas } \\
\text { (N e \%) }\end{array}$ \\
\hline Vivência no exterior & $\begin{array}{l}\text { Contato com pesquisadores empreendedores e/ou universidades } \\
\text { que facilitam o empreendimento durante intercâmbio acadêmico em } \\
\text { pesquisa. }\end{array}$ & 30 & $\begin{array}{c}13 \\
(54,2 \%)\end{array}$ \\
\hline $\begin{array}{l}\text { História de vida e } \\
\text { contexto familiar }\end{array}$ & $\begin{array}{l}\text { Vivências (incluem-se valores e crenças) na esfera familiar que } \\
\text { influenciaram o entrevistado a querer empreender. Aspectos da } \\
\text { história de vida do entrevistado que contribuíram para o interesse } \\
\text { por empreender }\end{array}$ & 20 & $\begin{array}{c}12 \\
(50,0 \%)\end{array}$ \\
\hline $\begin{array}{l}\text { Ter experiência de } \\
\text { mercado }\end{array}$ & $\begin{array}{l}\text { Experiências no mercado de trabalho antes, durante e, ou, depois do } \\
\text { ingresso na área docente. }\end{array}$ & 19 & $\begin{array}{c}6 \\
(25,0 \%) \\
\end{array}$ \\
\hline Ter empreendido & $\begin{array}{l}\text { Ter participado de um processo de criação de uma empresa no } \\
\text { passado. }\end{array}$ & 01 & $\begin{array}{c}1 \\
(4,2 \%)\end{array}$ \\
\hline
\end{tabular}

Fonte: dados da pesquisa - QDA Miner

Obs.: as subdimensões não são excludentes entre si, de maneira que os percentuais podem exceder $100 \%$.

Dos aspectos levantados, destaca-se, assim, "ter tido vivência no exterior", já que mais da metade dos entrevistados $(54,2 \%)$ relatou ter morado fora do país para realizar cursos ou intercâmbios acadêmicos, período considerado importante, no sentido de lhes permitir entrar em contato com outros docentes pesquisadores e empreendedores, como revelam os trechos:

"[...] em 2005 fui fazer meu pós-doutorado no Canadá, numa escola de negócios. Fui trabalhar com o professor F., muito conhecido no mundo pelo seu trabalho sobre empreendedorismo e tem muito dessa coisa do lado comportamental e a maneira como o empreendedor organiza o seu pensar [...]." (Entrevistado 9- docente empreendedor de universidade pública)

"[...] minha experiência com empreendedorismo começou muito antes lá no meu doutorado. Meu orientador, o professor G. da Universidade de W. tem esse perfil. Ele já criou onze empresas, criou empresas muito grandes [...]." (Entrevistado 8- docente empreendedor de universidade pública)

"[...] eu já tinha uma visão diferenciada, e com minha ida aos Estados Unidos eu vi que não tem dúvida. Nos Estados Unidos, o professor com o qual trabalhei, fazia parte de um projeto maior, em que participavam a universidade e a empresa, e depois eu achei maravilhoso porque eu fui convidado para fazer uma apresentação de trabalho no Canadá [...]." (Entrevistado 3 docente empreendedor de universidade pública)

Também chama a atenção o fato de apenas um participante ter relatado experiência prévia em empreender e seis terem tido alguma experiência no mercado de trabalho formal. Os dados apresentados por Duberley (2011) revelaram que, dos 23 participantes de um de seus estudos sobre o tema, nove relataram ter tido experiência prévia em empreender (via incubadora), enquanto que 18 tiveram experiência anterior em empresas (setor privado), diferentemente do que se encontrou na presente pesquisa. Tal contraste, em certa medida, corrobora a vivência no exterior como fator importante na trajetória de vida desses docentes/ pesquisadores para iniciarem um empreendimento, já que a falta de experiência no mundo dos negócios, seja como empreendedor ou colaborador em uma empresa, é uma característica mais comum entre os pesquisadores brasileiros do que para aqueles oriundos de países mais 
industrializados. E o contato anterior com o ambiente empresarial demonstra realmente ser um fator de estímulo para o docente/pesquisador, conforme trecho que se segue:

"[...] essa transição, da área acadêmica para área empreendedora, para mim não foi, como a gente acabou de concluir, uma surpresa, porque eu já vim do executivo e etc." (Entrevistado 15 - docente empreendedor de universidade privada)

Os demais aspectos identificados (História de vida e Contexto familiar) retrataram mais indiretamente o aprendizado do entrevistado com familiares que apresentavam comportamento empreendedor (por exemplo, habilidade para negociar) e/ou possuíam alguma empresa no mercado, atribuindo a essa convivência uma influência no próprio interesse de empreender.

\section{Motivos para a transição para o empreendedorismo}

No que se refere aos motivos da transição (TABELA 2), foram identificados aspectos que dizem respeito ao interesse em empreender (50 citações, em 75\% das entrevistas), ao fato de já estar desenvolvendo algum produto oriundo da pesquisa (34 citações, em 54,2\%), interesse do docente/pesquisador por ambas as áreas de atuação (16 citações, em 41,7\%), insatisfação com a carreira acadêmica (11 citações, em 20,8\%). E o fato de, ao longo de sua trajetória profissional, ter encontrado profissional que se tornou referência, estimulando a criação de um empreendimento (12 citações, em 33,3\% das entrevistas).

\section{Tabela 2 - Motivos da transição}

\begin{tabular}{|c|c|c|c|}
\hline \multicolumn{4}{|c|}{ Motivos da transição } \\
\hline Código & Descrição & Citações & $\begin{array}{l}\text { Entrevistas } \\
\text { (N e \%) }\end{array}$ \\
\hline Desejo de empreender & $\begin{array}{l}\text { Relatos que expressam um desejo ou interesse de empreender, } \\
\text { de fazer algo nessa área, ir além das funções na universidade, } \\
\text { muitas vezes em decorrência de oportunidades com as quais se } \\
\text { depararam. Associada ao desejo de empreender encontra-se } \\
\text { a ideia de missão, de deixar um legado e de fazer diferença na } \\
\text { sociedade, assim como contribuir para o crescimento do país. }\end{array}$ & 50 & $\begin{array}{c}18 \\
(75,0 \%)\end{array}$ \\
\hline $\begin{array}{l}\text { Desenvolvimento de } \\
\text { pesquisa/produtos }\end{array}$ & $\begin{array}{l}\text { O desenvolvimento de pesquisas influenciou a criação de um } \\
\text { empreendimento que desenvolvesse produtos para o mercado. }\end{array}$ & 34 & $\begin{array}{c}13 \\
(54,2 \%)\end{array}$ \\
\hline Interesse pelas duas áreas & $\begin{array}{l}\text { O interesse do entrevistado pelas duas áreas, acadêmica e } \\
\text { empreendedora, o levou ao ingresso no mundo dos negócios. }\end{array}$ & 16 & $\begin{array}{c}10 \\
(41,7 \%)\end{array}$ \\
\hline Profissionais de referência & $\begin{array}{l}\text { Profissionais que se tornaram referência para o entrevistado, seja } \\
\text { professores/pesquisadores ou mesmo profissionais de no meio } \\
\text { empresarial, influenciaram a decisão de empreender. }\end{array}$ & 12 & $\begin{array}{c}8 \\
(33,3 \%)\end{array}$ \\
\hline $\begin{array}{l}\text { Insatisfação a carreira } \\
\text { acadêmica }\end{array}$ & $\begin{array}{l}\text { As atividades atuais na academia (pesquisa e ensino) eram } \\
\text { insuficientes para a realização profissional, despertando o } \\
\text { interesse por algo novo, diferente. }\end{array}$ & 11 & $\begin{array}{c}5 \\
(20,8 \%)\end{array}$ \\
\hline
\end{tabular}

Fonte: dados da pesquisa - QDA Miner

Obs.: as subdimensões não são excludentes entre si, de maneira que os percentuais podem exceder o total de $100 \%$.

Muitos relatam a vontade de romper com o "academicismo" e atravessar as fronteiras da universidade, assim como "o desejo de empreender" $(75 \%)$ e ver na prática o funcionamento dos objetos de pesquisa, desenvolvendo produtos a partir das pesquisas como nos seguintes trechos: 
"Veja bem eu sempre tive vontade. A minha ambição na verdade, eu até o professor $A$. aqui também é assim, você sair do básico e tirar um produto, imagina você conseguir um produto?" (Entrevistado 11 - docente de Universidade pública)

"Tem muito a ver com a vontade de ver prova de conceito funcionando, não só tese de doutorado, uma dissertação de mestrado, um resultado de pesquisa, mas ver aquilo funcionando na internet, na web, os funcionários interessados em usar aquele ferramental, e, no momento que o interesse é muito grande, é natural que a gente crie um empreendimento [...] isso é uma maneira de você vê alguma coisa crescer, alguma coisa que você produziu". (Entrevistado 8 - docente empreendedor de universidade pública)

"Estar desenvolvendo um produto nas pesquisas" foi o segundo aspecto mais mencionado $(54,2 \%)$ pelos entrevistados como motivo para empreender. Alguns mencionaram o crescimento de um projeto de pesquisa que conduziu à criação de um produto viável para o mercado, enquanto outros, pela prática de desenvolver produtos em diferentes projetos, viram-se estimulados a empreender, como observado nas falas:

"[...] a gente foi começando a integrar as atividades de ensino e pesquisa, graduação e pós-graduação. Paulatinamente o curso foi crescendo e passamos a ser uma coisa importante dentro do nosso departamento. O laboratório passou a interagir uns com os outros e a gente criou, [...] no final da década de 80 e já no inicio da década de 90, o projeto que se chamou S., onde a gente começou a, pelo menos no Brasil, estudar a tecnologia da internet da web do ponto de vista do usuário." (Entrevistado 01 - docente empreendedor de universidade pública)

"Eu estou sempre envolvido com projetos, desenvolvendo projetos pra terceiros, mesmo antes dessa questão do meio da sociedade intelectual, de patentes, dessa corrida de cuidado de patentes de sigilo, quando projetos eu já fiz de mão aberta e fui embora, os indivíduos me contratavam pra fazer." (Entrevistado 04 - docente empreendedor de universidade pública)

$\mathrm{E}$ o fato de os docentes pesquisados estarem desenvolvendo produtos a partir das pesquisas acaba por gerar oportunidades que facilitam a entrada no mercado:

"[...] eles (representantes de um instituto de inovação) vieram aqui na universidade procurando quem pudesse ter produtos que podiam sair para o mercado etc., etc.; aí eles descobriram meu laboratório, meu filho e então foi uma confusão, eu nem lembro direito quais foram os procedimentos que a gente fez, aí a gente montou uma empresa, a empresa do meu filho que era dele, foi encampada pelo instituto de inovação e eu entrei participando dessa empresa" (Entrevistada 10 - docente empreendedora de universidade pública)

Alguns desses docentes mencionaram que também almejam conseguir melhores empregos para seus alunos. Eles relatam que se sentem compelidos a inventar, ir ao mercado e, assim, fazer com que seu trabalho seja reconhecido, assim como absorver os profissionais que ajudaram a desenvolver:

"[...] mas foi uma questão de um grupo, um grupo e muito esse ímpeto de um nosso professor: "Não, a gente tem que levar esses resultados nossos para fora, isso traz riqueza para o país, divulga a universidade, cria empregos de qualidade para os nossos alunos." (Entrevistado 1 - docente empreendedor de universidade pública)

"[...] eu acho que o que levou a gente a fazer e a construir a empresa foi um pouco da experiência do dia a dia [...]. E a gente pensou: 'Poxa a gente está sempre formando gente e começando do zero toda vez. Será que se a gente não tivesse uma empresa a gente, não podia segurar essa mão de obra que a gente está formando?' (Entrevistada 7 - docente empreendedora de universidade pública)

Outro motivo apresentado por quase a metade dos entrevistados $(41,7 \%)$ refere-se ao 
reconhecimento do interesse tanto pela academia como pelo empreendedorismo:

"Eu pensava desde mocinho, eu tinha uma imagem do professor muito forte, assim uma pessoa que ajuda as pessoas, é o modelo, é uma referência para o jovem, e também, ao mesmo, eu tive vontade de ser empreendedor. Duas coisas que eu me vejo, assim, que são muito fortes em mim." (Entrevistado 22 - docente empreendedor de universidade pública)

E apenas oito participantes mencionaram ter se inspirado em um profissional da área e que já atuava como empreendedor, apontando algumas características consideradas importantes para esse ramo de atividade (p. ex., agressividade no mercado, ousadia, maturidade).

Tive em contato direto com o L.H. que era um grande estrategista... então, foi um crescimento porque como químico eu precisava de um pouco de ideia de gestão." (Entrevistado 24 - docente empreendedor de universidade privada)

Para cinco docentes, o direcionamento para o empreendedorismo foi motivado por insatisfação com a universidade e com a carreira acadêmica. Para esse grupo, as atividades atuais na academia (pesquisa e ensino) foram, ao longo do tempo, ficando insuficientes para a realização profissional, despertando o interesse por algo novo, diferente.

\section{Conclusões}

As conclusões deste trabalho estão organizadas de acordo com as dimensões de análise que o nortearam, definidas a partir dos objetivos e do referencial teórico, nas quais se espelharam as questões do roteiro de entrevista, de maneira a gerar uma coerência interna no projeto.

No que se refere, assim, à trajetória familiar e profissional, o aspecto que mais se destacou como influenciador da decisão de empreender foi o contato no exterior com universidades com tradição no que se refere ao incentivo ao empreendedorismo, assim como com pesquisadores empreendedores.

Ao discorrer sobre os motivos que os levaram a transitar para o empreendedorismo, os docentes apontam a vontade de ir além das atividades exercidas na universidade, assim como o desejo de empreender e de levar o conhecimento nela gerado para o mercado, resultados esses semelhantes aos encontrados por Duberley, Cohen e Leeson (2007) e por Duberley (2011). Esses motivos também estariam ligados às oportunidades que surgiram, via de regra, por meio de colegas ou pessoas da comunidade acadêmica.

Associada ao desejo de empreender encontra-se a ideia de missão, de deixar um legado e de fazer diferença na sociedade, assim como contribuir para o crescimento do país, o que seria capaz lhes propiciar um sentimento de grande realização pessoal. Alguns entrevistados apontaram a possibilidade de ganhos financeiros, mais como uma consequência natural do negócio do que uma motivação para a transição.

Os motivos para a transição revelaram-se de natureza voluntária e não decorrentes de fatores tais como demissão ou queda do poder aquisitivo, assim como encontrado por Duberley, Cohen e Leeson (2007) e Duberley (2011), em suas pesquisas com o mesmo público.

Em alguns casos, as oportunidades contribuíram para a transição, mas, de modo geral, suas necessidades internas os impulsionaram e lhes deram forças para resistir às dificuldades e preconceitos que encontram na própria universidade, além da intensa concorrência que enfrentam no mundo empresarial.

A possibilidade de desenvolver um produto viável para o mercado, como desdobramento da pesquisa, também os incentiva naturalmente a partir para o empreendedorismo.

Quanto à influência dos contextos institucionais na transição, sobressaíram aspectos 
limitantes, tais como o conservadorismo acadêmico, principalmente no que se refere à desvalorização da prática empreendedora advinda da pesquisa tecnológica.

Já o ambiente empresarial é destacado pelo seu dinamismo em adaptar o processo de produção e qualidade dos serviços prestados, em decorrência das mudanças nas demandas do mercado. A própria competitividade, característica desse ambiente, é vista como importante para estimular a busca por melhorias e produtos inovadores, assim como um desafio para que a empresa se firme no mercado.

De modo geral, os docentes tentam permanecer na carreira acadêmica, assim como encontrado por Duberley, Cohen e Leeson (2007) e Duberley (2011), e para tal, buscam parcerias de pessoas e empresas que os possam ajudar a desenvolver o seu negócio. $E$ a inserção no empreendedorismo necessita ser feita de maneira a se conciliar a carreira acadêmica com a empresarial. As parcerias tornam-se, assim, peças fundamentais para que o professor possa viabilizar essa dupla atuação, assim como o apoio institucional, com o qual nem sempre podem contar, quando não enfrentam dificuldades e resistências por parte de colegas e da própria universidade.

Deduz-se, também, deste estudo que o mundo empreendedor, agências governamentais e universidades poderiam se articular de maneira mais eficiente, proporcionando um adequado suporte para que esses docentes empreendedores possam desenvolver seus negócios de modo mais efetivo.

\section{Contribuição do estudo}

De acordo com Bastos (2011), a reflexão sobre as transformações e transições nos domínios dos estudos organizacionais e, principalmente, no campo das carreiras, constitui atualmente um imperativo para pesquisadores e gestores. Duberley (2011) também discute acerca da relevância de estudos que abordam esta temática, apontando a necessidade de uma teoria sobre transição ocupacional, em que se considerem tanto aspectos contextuais como individuais. Essa autora considera o profissional que transita da carreira acadêmica para o empreendedorismo como aquele que possui uma posição ideal para captar a interação entre transições de carreiras individuais e contextos mutantes de carreira. Embora já tenham sido realizadas pesquisas nacionais centradas na mobilidade do trabalho acadêmico (LACOMBE, 2005), existem poucos trabalhos empíricos que abordam as formas objetivas e subjetivas de transição de carreira. Em síntese, o projeto focalizou mudanças nas carreiras de pesquisadores e docentes que empreendem. Seu impacto reside na ampliação do conhecimento sobre as transições de carreira, de modo geral, e sobre este tipo específico de transição, que tende a ocorrer de maneira mais frequente, considerando os incentivos por parte da sociedade, do governo e das próprias universidades, no sentido de estreitarem os laços da academia com o mundo corporativo.

\section{Referências Bibliográficas}

ALVES-MAZZOTTI, A. J.; GEWANDSZNAJDER, F. O método nas ciências naturais e sociais: pesquisa quantitativa e qualitativa. São Paulo: Thomson, 1999.

ARBER, S. Designing samples. In: GILBERT, N. (Ed.). Researching social life. London: Sage, 2001. p. 58-84.

AUDI, Jorge Luís Nicolas; MOROSINI, Marília Costa (Org.). Inovação e empreendedorismo na universidade. Porto Alegre: EDIPUCRS, 2006.

BAETA, Adelaide M.C.; SANTARITA, Cleverton. A contribuição das Incubadoras de Empresas de Base Tecnológica ao processo de inovação e desenvolvimento local. In: 
SEMINÁRIO IBEROAMERICANO DE CIÊNCIA Y TECNOLOGIA- IBERGECYT, 6., 2008, Havana. Anais... Havana, Cuba: [s. n.], 2008.

BARDIN, L. Análise de conteúdo. Lisboa: Edições Setenta, 2006.

BARLACH, Lisete; MALVEZZI, Sigmar. ReCaPe - Revista de Carreiras e Pessoas, São Paulo, v. 02, n. 02, maio/jun./jul./ago. 2012.

BARUCH, Y. Transformações nas Carreiras: de trajetórias lineares para multidirecionais. Perspectivas organizacionais e individuais. In: KILIMNIK, Z. M.(Org.) Transformações e Transições nas Carreiras: estudos nacionais e internacionais sobre o tema. Rio de Janeiro: QualityMark, 2011. 296 p.

BENDASSOLLI, Pedro F.; WOOD JR., Thomaz. O paradoxo de Mozart: carreiras nas indústrias criativas. O\&S, Salvador, v.17, n. 53, p. 259-277, abr./jun. 2010.

CASTRO, Alexandre Camargo; JANNUZZI, Celeste Aída Sirotheau Correa; MATTOS, Fernando Augusto Mansor. Produção e disseminação de informação tecnológica: a atuação da Inova - Agência de Inovação da UNICAMP. TransInformação, Campinas, v. 19, n. 3, p. 265277, set./dez. 2007.

CLOSS, Lisiane et al. Intervenientes na transferência de tecnologia universidade-empresa: o caso PUCRS. RAC, Rio de Janeiro, v. 16, n. 1, p. 59-78, jan./fev. 2012.

DOMINGUES, Leonardo. O empreendedorismo e as novas práticas do fazer científico. Intratextos, Rio de Janeiro, v. 4, n. 1, p. 137-159, 2012.

DORNELAS, J. C. A. Transformando ideias em negócios. 2. ed. Rio de Janeiro: Elsevier, 2005.

DRUCKER, P. F. Inovação e perfil empreendedor (Entrepreneurship): prática e princípios. São Paulo: Pioneira, 1986.

DUBERLEY, J. Avaliando Transições Profissionais: da carreira científica para o empreendedorismo por meio de incubadoras de empresas In: KILIMNIK, Z. M. (Org.) Transformações e Transições nas Carreiras: estudos nacionais e internacionais sobre o tema. Rio de Janeiro: QualityMark, 2011. 296 p.

DUBERLEY, J.; COHEN, L.; LEESON, E. Entrepreneurial academics: Developing scientific careers in changing university settings. Higher Education Quarterly, [S. I.], p. 479-497, 2007.

DUBERLEY, J.; COHEN, L.; MALLON, M. Constructing scientific careers: change, continuity and context. Organization Studies, [S. I.], v. 27, n. 8, p. 1131-1152, 2006.

FILION, Louis Jacques; DOLA, Fernando. Boa Ideia! e agora? Plano de negócios, o caminho seguro para criar sua empresa. São Paulo: Cultura Editores Associados, 2000.

GOMES et al. Âncoras e metáforas de carreiras entre universitários. RPCA, Rio de Janeiro, v. 6 , n. 4, p. 106-123, out./dez. 2012.

GUEDES, Simone Alves. A carreira do empreendedor. 2009. 150 f. Dissertação (Mestrado em Administração) - Departamento de Administração da Faculdade de Economia, Administração e Contabilidade da Universidade de São Paulo, São Paulo, 2009.

GUERRA, Paulo Vítor; GOMES, Daniel Teodoro; CHENG, Lin Chih. Universidade empreendedora: o caso do Programa de Incentivo à inovação. In: ENCONTRO DA ASSOCIAÇÃO NACIONAL DE PÓS-GRADUAÇÃO E PESQUISA EM ADMINISTRAÇÃO, 35., 2011, Rio de Janeiro. Anais... Rio de Janeiro: ANPAD, 2011.

IPIRANGA, Ana Sílvia Rocha; FREITAS, Ana Augusta Ferreira de; PAIVA, Thiago Alves. O empreendedorismo acadêmico no contexto da interação universidade - empresa - governo.

CADERNOS EBAPE. BR, Rio de Janeiro, v. 8, n. 4, p. 676-693, dez. 2010. 
KILIMNIK, Zélia M.; CASTILHO, Isolda V.; SANT'ANNA, Anderson S. Carreiras em transformação: um estudo de trajetórias, âncoras e metáforas de carreira em associação a representações de competências profissionais. In: ENCONTRO DAASSOCIAÇÃO NACIONAL DE PÓS-GRADUAÇÃO E PESQUISA EM ADMINISTRAÇÃO, 28., Curitiba. Anais... Rio de Janeiro: ANPAD, 2004.

MACHADO, Layla B. C. V. Confrontando motivos e imagens relacionados à carreira: um estudo com profissionais de nível superior que se direcionam para o setor público. 2009. 150 f. Dissertação (Mestrado em Administração) - Faculdade de Ciências Empresariais - FACE, Universidade FUMEC, Belo Horizonte, 2009.

MORAES, Roque. Análise de conteúdo. Revista Educação, Porto Alegre, v. 22, n. 37, p. 7-32, 1999.

MORO, M., SANCHEZ-CRIADO, T. Taller de metodología de investigación - parte II. Herramientas básicas para la investigación cualitativa: introducción al manejo del programa de análisis cualitativo QDA Miner 1.2. Manuscrito en desarrollo. Madrid: UAM. 2005.

MUSCIO, A. What drives the university use of technology transfer offices? Evidences from Italy. Journal of Technology Transfer, v. 35, n. 2, p. 181-202, 2010.

NASSIF, Vânia Maria Jorge et al. A universidade desenvolve competências empreendedoras? Um mapeamento das práticas de ensino numa universidade brasileira. In: ENCONTRO DE ENSINO E PESQUISA EM ADMINISTRAÇÃO E CONTABILIDADE, 3., 2011, João Pessoa. Anais... Rio de Janeiro: ANPAD, 2011.

NEVES, Mônica Maria; TREVISAN, Wilson; PETROKAS, Leandro Augusto. A transição de carreira de executivos seniores para carreira Empreendedora. ReCaPe - Revista de Carreiras e Pessoas, São Paulo, v. 01, n.02, set./out./nov./dez. 2011.

NICHOLSON, N.; WEST, M. A. Managerial job change: men and women in transition. Cambridge, UK: Cambridge University Press, 1988.

NICOLAU, N.; BIRLEY, S. Academic networks in a trichotomous categorization of university spinouts. Journal of Business Venturing, [S. I.], v.18, p. 333-359, 2003.

PETERS, M. P.; HISRICH, R.D. E SHEPERD, D. A. Empreendedorismo. Porto Alegre: Bookman, 2009.

PINOTTI, Saulo Taffarello. Profissionais técnicos e a opção de carreira pelo empreendedorismo: um estudo exploratório. 2009. 176 f. Dissertação (Mestrado em Administração de Empresas) - Escola de Administração de Empresas de São Paulo, da Fundação Getúlio Vargas, São Paulo, 2009.

PÓVOA, L. M. C.; RAPINI, M. S. Technology transfer from universities and public research institutes to firms in Brazil: what is transferred and how the transfer is carried out. Science and Public Policy, [S. I.], v. 37, n. 2, p. 147-159, 2010.

LOUIS, Meryl Reis. Career transitions: Varieties and commonalities. Academy of Management Review, [S. I.], v. 5, p. 329-340, 1980.

RELATÓRIO Anual de 2007. Empreendedorismo no Brasil. Disponível em: <http:// www.sebraemg.com.br/arquivos/programaseprojetos/educacaoempreendedorismo/ globalentrepreneurshipmonitor/gem2006.pdf>. Acesso em: 10 mar. 2008.

RIMOLI, Celso A.; ANDREASSI, Tales; GOUVÊA, Rodrigo; ZANATTA, Jeanlins B. Reflexões sobre empreendedorismo: estudo de caso de empresas de sucesso e insucesso. In: ECONTRO DA ASSOCIAÇÃO NACIONAL DE PÓS-GRADUAÇÃO E PESQUISA EM ADMINISTRAÇÃO, 28., 2004, Curitiba. Anais... Rio de Janeiro : ANPAD, 2004. (CD-ROM).

RIVERIN-SIMARD, Danielle. Transitions profissionelles : choix et stratégies. Québec: Le 
Press de L'université de Laval, 1993.

ROBBINS, S. P. Administração: mudanças e perspectivas. São Paulo: Saraiva, 2001.

SANT'ANNA, Anderson S. Profissionais mais competentes, políticas e práticas de gestão mais avançadas? RAE-eletrônica, [S. I.], v. 7, n. 1, jan./jun. 2008. Disponível em <http:// www16.fgv.br/rae/eletronica/index.cfm?FuseAction=Artigo\& ID=3908\&Secao=ARTIGOS\&Vol ume $=7$ \&numero $=1 \& A n o=2008>$.

SANTANA, E.; PORTO, G. E agora, o que fazer com essa tecnologia? Um estudo multicaso sobre as possibilidades de transferência de tecnologia na USP-RP. Revista de Administração Contemporânea, [S. I.], v. 13, n. 3, p. 410-429, 2009.

SANTOS, Neusa M. B. L.; ABRAHIM, Gisele S. A influência dos valores pessoais na determinação das âncoras de carreira. In: ENCONTRO DA ASSOCIAÇÃO NACIONAL DE PÓS-GRADUAÇÃO E PESQUISA EM ADMINISTRAÇÃO, 32., 2008, Rio de Janeiro. Anais... Rio de Janeiro: ANPAD, 2008.

SARASVATHY, S. D. The questions we ask and the questions we care about: reformulating some problems in entrepreneurship research. Journal of Business Venturing, [S. I.], p. 1-11, 2004.

SCHUMPETER, A. S. Teoria do desenvolvimento econômico: uma investigação sobre lucros, capital, crédito, juro e ciclo econômico. São Paulo: Nova Cultural, 1997.

SHANE, Scott; VENKATARAMAN, S. The promise of entrepreneurship as a field of research. Academy of Management Review, [S. I.], v. 25, n. 1, p. 217-226, 2000.

SILVA, Luiz Fernando Soares da; REIS, Márcia Cristina dos; STURION, Leonardo. A importância do empreendedorismo como fator de inovação na educação. UNOPAR Cient., Ciênc. Human. Educ., Londrina, v. 13, n. 1, p. 85-90, jun. 2012.

SOUZA, Carla Patricia da Silva; TAKAHASHI, Adriana Roseli Wünsch. Processo de intraempreendedorismo e mudança organizacional em uma organização universitária pública brasileira. In: ENCONTRO DE ESTUDOS EM EMPREENDEDORISMO E GESTÃO DE PEQUENAS EMPRESAS (EGEPE), 8., 2014, Goiânia. Anais... Goiânia: EGEPE, 2014.

SOUZA, Elnivan Moreira de et al. Comportamento empreendedor e crescimento de empresas: uma análise comparativa. Scientia, [S. I.], ano 01, p. 192 - 395, nov. 2012/jun. 2013.

TAVARES, C. Moreira; MOURA, G. Luiz de; ALVES, J. Nunes. Educação empreendedora e a geração de novos negócios. Observatorio de la Economía Latinoamericana, [S. I.], n. 188, 2013.

TIEPPO, Carlos Eduardo et al. Seriam as âncoras de carreira aderentes às carreiras inteligentes? Estudo comparativo entre alunos formandos do curso de Administração de Empresas e Turismo. RGO - Revista Gestão Organizacional, [S. I.], v. 4, n. 2, p. 144-154, jul./ dez. 2011.

VELOSO, E. F. V. Carreiras sem fronteiras e transição profissional no Brasil: desafios e oportunidades para pessoas e organizações. São Paulo: Atlas, 2012.

VERGARA, Sylvia Constant. Métodos de pesquisa em administração. 3. ed. São Paulo: Atlas, 2008.

VIEIRA, M. M. F. Por uma boa pesquisa (qualitativa) em administração. In: VIEIRA, M. M. F.; ZOUAIN, D. M. (Org.). Pesquisa Qualitativa em Administração. Rio de Janeiro: FGV, 2004. cap. 1, p. 13-19. 